\title{
Questions for Biotechs: REIVAC
}

\section{Pierre Loulergue, Xavier Duval, Florence Galtier, Nezha Lenzi, Henri Laurichesse \& Odile Launay}

To cite this article: Pierre Loulergue, Xavier Duval, Florence Galtier, Nezha Lenzi, Henri Laurichesse \& Odile Launay (2011) Questions for Biotechs: REIVAC, Human Vaccines, 7:2, 142-143, DOI: $10.4161 / \mathrm{hv} \cdot 7.2 .15130$

To link to this article: http://dx.doi.org/10.4161/hv.7.2.15130

\section{(2) Copyright (c) 2011 Landes Bioscience}

册 Published online: 01 Feb 2011.

Submit your article to this journal

Џ Article views: 31

Q View related articles $₫$ 


\section{Human Vaccines: Profile}

\section{Questions for Biotechs}

\section{REIVAC}

Pierre Loulergue, Xavier Duval, Nezha Lenzi, Henri Laurichesse and Odile Launay; Email: odile.launay@cch.ap-hop-paris.fr

\section{All author are part of the REIVAC network.}

How and when did your organization start, and where are you located?

The REIVAC, French Clinical Research Network in Vaccinology (in French REseau national d'Investigation en VACcinologie), was created in 2007 by four clinical research sites working, partially or exclusively, in the field of vaccines. Each institution is experienced in both academic and industrial clinical research. The network is officially supported and sponsored by several public and private institutions (Inserm: National Institute of Health and Medical Research and GIP CeNGEPS: Group of Public Interest from the National Management trial Centre for Health Products). Since 2008, seven other clinical centers have joined the network.

The coordination of the REIVAC is run by Dr. Odile Launay, infectious diseases specialist and head of the Clinical Research Centre for Vaccinology Cochin Pasteur, located at Cochin Hospital in Paris.

What are the most critical problems in vaccine development in your field of interest?

One of our main hurdles in research is the vaccination of subjects whose immune system is altered by conditions such as extremes of age, HIV infection, immunosuppressive treatment for solid organ transplant, solid or hematologic cancers or autoimmune diseases. Protecting those subjects efficiently is a real challenge today, and research clinicians have to work closely with scientists and companies in order to develop more immunogenic vaccines and improve routes of vaccine administration.

From an organizational point of view, clinical research in vaccinology requires more international collaborations between clinical research centers. Working with other countries requires important funding, and public grants are still rare.

\section{What is the mission of your organization?}

The REIVAC's mission is to improve the attractiveness of France for the implementation of preventive and therapeutic vaccine trials, from preclinical to clinical phases, and to link up scientists and physicians as well as industries and academic institutions to develop exploratory research in vaccinology.

\section{How does your organization facilitate vaccine development?}

Our strengths are to have a centralized coordination team, closely working with a steering scientific committee, which gives REIVAC the power to answer solicitations from industrial companies or academic research teams with great reactivity. We also facilitate financial and hospital agreements validation to reduce the administrative delays.

Moreover, the REIVAC can provide scientific, clinical and technical expertise in vaccines to ensure high standards for trials, and the clinical research centers composing the network may ease the recruitment of healthy volunteers and/or patients. Optimal safety is guaranteed, especially for early phases, by adapted procedures and experienced teams.

How does your organization engage national and international resources committed to vaccine research?

REIVAC is funded by the GIP CeNGEPS and the Inserm. We receive funds annually, after validation of our activity reports. Those funds allow us to hire the coordination team and several clinical research assistants located in the different clinical centers of REIVAC.

The primary role of these research assistants is to help recruit participants. The coordination team coordinates the network; it is composed of a clinical study coordinator, a clinical research pharmacist, a quality engineer and a clinical research assistant. We also organize national scientific meetings where scientists, clinicians and industrials can share their works and build new clinical studies.

What important partnerships does your organization have?

We are working with academic partners such as Inserm, Institut Pasteur, Paris Descartes University, the CEA (French Alternative Energies and Atomic Energy Commission), the ANRS (French AIDS Research Agency); and also pharmaceutical companies like GSK Biologicals, SanofiPasteur, Merck, Sanofi-Pasteur-MSD, Transgene, and Becton Dickinson.

\section{What is your function at your organization?}

As founding members of REIVAC we form the steering committee and provide the strategic directions of the network.

What were your "highlights" in recent vaccine research, development, or use?

The REIVAC has been strongly involved in studies of influenza vaccination with the $\mathrm{H} 1 \mathrm{~N} 1$ pandemic vaccine and the seasonal vaccine. It is also involved in a clinical trial with a Staphylococcus aureus vaccine in adult patients scheduled for cardiothoracic surgery and clinical trials with an adjuvant immunotherapy using an antigen specific for melanoma cancer.

Currently the REIVAC is in clinical trials for a zoster vaccination, to evaluate its efficacy in immunocompromised patients; but also in therapeutic vaccine in patients with lung cancer.

What areas or topics does your organization currently focus on? The REIVAC is focusing on early phase clinical trials and studies aiming at increasing the immunogenicity of vaccines in immunocompromised hosts.

What are your main goals for the next five years?

Our objectives are to improve, harmonize and facilitate the recruitment of volunteers in our clinical centers; to generate more vaccine trials in 
France and in the European Community; to evaluate innovative concepts resulting from the basic science; to set up a biobank; and finally to extend scientific and medical knowledge in vaccinology, especially in immunocompromised patients.

For more information, please visit: www.reivac.com
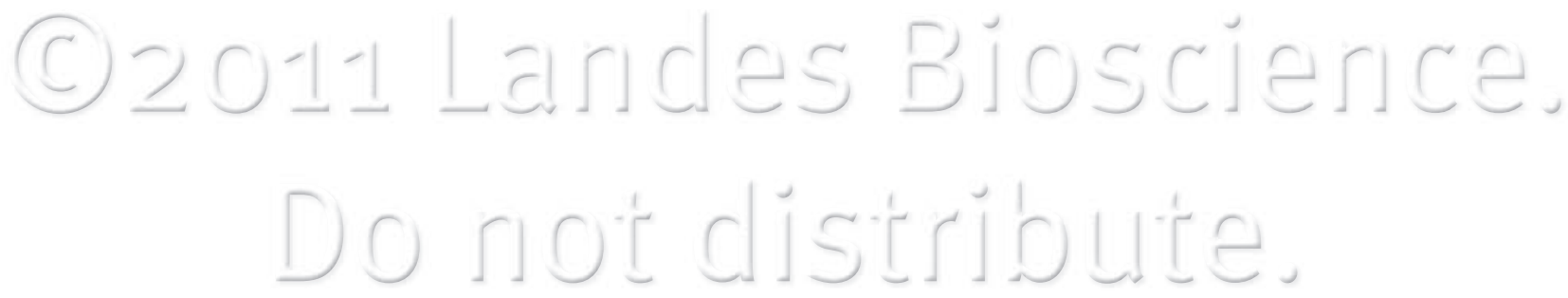